ARTICLE

DOI: $10.1057 /$ s41599-018-0107-7

\title{
Discourses of technology, ageing and participation
}

\author{
Aysha Fleming ${ }^{1}$, Claire Mason ${ }^{2} \&$ Gillian Paxton ${ }^{3}$
}

\begin{abstract}
The proliferation of digital technology has brought about rapid social and economic change, the consequences of which have not been evenly distributed. Older people, in particular, tend to be less engaged with digital technology and as a result, are said to be at risk of 'digital exclusion'. In this paper, we explore how digital technology is discursively linked to ageing and social and economic participation. The analysis is based on 38 interviews with representatives of industry, government and civil society asked to share their views of the opportunities and risks associated with age and participation in the context of rapid developments in digital technology. Using discourse analysis we identify two competing ways interview participants made connections between digital technology and its perceived effects on the economic and social participation of an ageing population. In the first, digital technology drives human progress as a ' $\mathrm{fix}^{\prime}$ to some of the social and economic challenges associated with ageing but also demands a cautious approach to minimise unforeseen negative consequences. In the second, digital technology is a tool, whose development can be driven by humans in order to solve a range of problems, including economic and social participation in later life. We consider the implications of these two discourses, discussing the potential of each for achieving a sense of empowerment in the ageing community and addressing the challenge of lifelong participation.
\end{abstract}

\footnotetext{
${ }^{1}$ CSIRO, Land and Water, Castray Esplanade, Hobart, Battery Point 7000, Australia. ${ }^{2}$ CSIRO, Land and Water, Dutton Park, Brisbane 4001, Australia.

3 University of Queensland, Brisbane 4072, Australia. Correspondence and requests for materials should be addressed to

A.F. (email: Aysha.Fleming@csiro.au)
} 


\section{Introduction}

$\mathrm{n}$ Australia and around the world the population is ageing. Increased life expectancies, combined with a falling birth rate mean that the ratio of working age to $65+$ adults is falling. The United Nations (Department of Economic and Social Affairs, 2015) predicts that, by 2050, all major areas of the world except Africa will have nearly a quarter or more of their populations aged 60 or over. This demographic disruption is occurring alongside rapid advances in digital technology.

In a paper exploring the role of digital technology in society, Castells (1998) argued that the ability to access, use and adapt information and communication technologies is 'the critical factor in generating and accessing wealth, power, and knowledge in our time' (p. 92). Terms such as 'digital transformation', 'digital disruption' and 'digital inclusion' reflect the substantial impact that digital technology has on the way in which we live and work, and the importance of being able to use and access digital technology to participate in contemporary society. The concept of the 'digital divide' has arisen through research that has shown that what people do online increasingly reflects (and exacerbates) offline economic, social, and cultural disparities (e.g., Hodge et al., 2016; van Deursen et al., 2015; Abbey and Hyde, 2009). Economic, social and cultural systems shape experiences with digital technology just as they do interactions and experiences in the offline world. Consequently, demographic and digital disruption are not just occurring side by side; they are likely to interact in their effects.

This paper builds on the work of others who look at technology discourses (e.g., Turner, 2006; Fisher, 2010; Kozinets, 2008; Buchanan-Oliver and Cruz, 2011) or discourses of ageing (e.g., Madden and Cloyes, 2012; King, 2013; Fealy et al., 2012) or less commonly, age and technology in combination (e.g., Vines et al., 2015). The work done in this field so far suggests important ways that discourses constrain our decisions and actions, by seeing ageing as a 'problem', or an 'illness' or a 'deficit', for example (Vines et al., 2015) while technology is more often be portrayed as 'equalising', 'value free' and 'universal' (Fisher, 2010). Turner (2006) and Mosco (2004) have critiqued this myth of 'techtopia' where technology is seen as having the potential to transform society and solve all problems while instead actually reinforcing existing power structures and cultures of western, white, rich, privilege. Fisher (2010) also links ideas of techtopia to capitalism and the economy whereby technology is viewed as positively disrupting work and money-making processes, but ultimately often ends up reinforcing the status quo. Kozinets (2008) and Buchanan-Oliver and Cruz (2011) have looked at other discourses of technology relating to how technology is mediated by (and mediates) self-identity and ideology to the point where technology becomes inseparable from the self.

Whereas analysis of technology discourses reveals diverse ways technology is normalised to affect individuals and society, discourses of ageing mostly portray older people as separate from mainstream society (Fealy et al., 2012). Fealy et al. (2012) identified five ways that older people were constructed, namely 'victims', 'frail, infirm and vulnerable', 'radicalised citizens', 'deserving old' and 'undeserving old'. King's (2013) analysis of discourses of ageing (informed by feminist theory and focused on works of fiction) found that post-menopausal women are not just separate but are effectively an 'invisible generation'. Focusing on participation and later life, Taylor and Earl (2015) identify the inadequacy of the policy discourses around working longer considering the diversity within aged (and all) demographics. Arguably, as the capability of digital technology continues to develop it can potentially change the way in which we participate, perhaps even challenging our notions of participation becoming more limited later in life. This potential is evident in current research and policy on the topic of the 'future of work' and how technological developments are affecting the nature of work and work arrangements (e.g., Brynjolfsson and McAfee, 2014; Dolphin, 2015; Ford, 2015; Hajkowicz et al., 2016). On the other hand, the more negative discourses of ageing may be so embedded that they constrain this potential-e.g., if older people are considered insufficiently skilled or motivated to engage with digital technology (Ford, 2015). It is therefore important to examine how discourses of ageing and technology interact in discussions about participation, later life and developments in digital technology. This study provides an opportunity to explore what discourses emerge in the context of these topics and, from this, to identify how our ways of thinking about ageing and technology serve to constrain or privilege certain ways of participating in later life.

Research linking age and technology. There has already been considerable prior research examining the relationship between age and digital technology which reflects the interplay of multiple factors such as education, occupation, family and geographical locations as well as factors related to later life-stages such as changing work arrangements or retirement and children leaving home (Boulton-Lewis et al., 2007; Comunello et al., 2016; Fernández-Ardèvol, 2013; Kuoppamaki et al., 2017; Prendergast and Garattini, 2015; Nixon et al., 2016; Bennett et al., 2008; Helsper and Eynon, 2010; White and Le Cornu, 2011). Nevertheless, as opportunities and services are increasingly, and sometimes exclusively, delivered through online channels, there is a risk that older people will become further alienated from aspects of social and economic life facilitated by digital technology. The increased automation of work enabled by digital technology will result in human workers being displaced and labour market shocks of this kind are known to have a disproportionately high effect on older workers (Ahituv and Zeira, 2011; Murtough and Waite, 2000; Weller, 2007). Older workers who are less digitally literate and have less time to dedicate to reskilling for new jobs may choose to retire early from economic participation. Social connections with family, friends and communities increasingly require the willingness and ability to engage through digital communication channels. On the other hand, older people who are willing (and able) to engage with digital technology may be able to find new alternative sources of income, social connection and productive and meaningful activity that are now (and increasingly) available through digital platforms (Dane et al., 2013). The combination of digital and demographic disruption could therefore have very significant impacts. Critical analysis of current discourses relating to age and digital technology is vital to explore how they might shape our thoughts and actions and potentially constrain the possibilities associated with digital technology in an ageing population.

Our focus in this paper is the age-technology-participation nexus. In conducting the research we were interested in instances where technology might enable new ways of participating, without focusing on any one cohort in particular (e.g., retired, not retired). This is a subtle departure from much of the literature on technology and ageing which more often focuses on a specific group and existing technology and provides recommendations for maximising uptake or positive impact (Selwyn et al., 2003; Damodaran and Sandhu, 2016; Damant and Knapp, 2015; Tsai et al., 2015; Thomas et al., 2016).

Discourse analysis. The term 'discourse' relates to socially and historically mediated constructions of language. While there is more than definition of discourse and thus differing approaches to discourse analysis, we adopt Kress's definition (1985, p 7): ‘A 
discourse provides a set of possible statements about a given area, and organises and gives structure to the manner in which a particular topic, object, process is to be talked about. In that it provides descriptions, rules, permissions and prohibitions of social and individual actions'. Therefore, discourses influence the ways individuals think, speak and act in different situations. Fluid, dynamic and constituted in social practices, discourses are inherently political; they simultaneously reflect and enact systems of power (Foucault, 1972, 1980). Some discourses are given greater authority by certain cultural groups and are perceived as having greater legitimacy. These dominant discourses are often normalised as 'common sense', while other discourses are marginalised or disdained. Discourses have a normative effect, creating taken-for-granted frameworks around which ideas of what is right and wrong, normal or abnormal, and possible or impossible, are perpetuated (Foucault, 1972, 1980; Kress, 1985; Jorgensen and Phillips, 2002; Fleming and Vanclay, 2014).

By paying close attention to discourses, social scientists are able to gain a valuable awareness of how social reality is constructed and perpetuated through language. Discourse analysis is a rich area of study within the social sciences that seeks to systematically explore and examine patterns that construct and perpetuate social differences and social issues. It seeks to deconstruct 'taken for granted' structures to show that how the world is organised is the result of social and political processes that have particular consequences and could be arranged differently (Jorgensen and Phillips, 2002)

Ultimately, this type of research also critically evaluates how discursive frameworks may be challenged and changed to achieve better and fairer outcomes. There are many different methods and proponents of discourse analysis, including linguistic analysis, conversation analysis, concrete relationships with the material world, power and agency, actor networks, historical and genealogical analysis, frame analysis, cultural anthropology, governance, political and psychological interpretations (Foucault, 1972, 1980; Kress, 1985; Hajer, 1995; van Dijk, 2001; Laclau and Mouffe, 1985; Fernback, 2007; Badham, 2008; Angermuller, 2015, Angermuller et al., 2014: Jorgensen and Phillips, 2002 provide useful reviews). We situate our work within a poststructural theory paradigm (meaning is not fixed and truth is relational), informed by Foucault $(1972 ; 1980)$ and Kress (1985) and using a critical discourse analysis approach following Fairclough (1992; 1995).

Our focus is on the discourses surrounding digital technology in the context of social and economic participation in later life. In the first instance, these discourses have implications for the way in which technology is designed (who it is designed for and by) and applied (in what contexts, for what uses). Ultimately, they affect how older people use digital technology and thus their ability to participate on an equal basis with other members of society.

In this study we empirically examine the discourses of key decision makers representing a broad range of sectors relevant to the older age group (e.g., health, education, transport, finance, volunteering, aged care, government). Analysing interview material captured from these high-level representatives allows us to build upon existing literature on discourses of technology and age (e.g., Turner, 2006; Fisher, 2010; Kozinets, 2008; Buchanon-Oliver and Cruz, 2011; Vines et al., 2015) by focusing on these discourses in the context of social and economic participation-as expressed by thought leaders and key decisionmakers in Australian society.

\section{Methods}

Interviews. The data for this research was interview transcripts gathered for a thought-leadership report on digital technology, age and participation (Mason et al., 2017). Interviews are wellsuited to discourse analysis since they allow us to examine language in use and draw out the links between texts (in this case the interviews) and societal and cultural processes and structures (Jorgensen and Phillips 2002). Since the interviews were carried out with thought leaders (very senior representatives of government and private sector organisations), they provide insight into accepted and influential ways of talking about and thinking about digital technology, ageing and participation. Thirty-eight interviews were conducted between February and April 2016. Most interviews were carried out over the phone and lasted between 45 and $60 \mathrm{~min}$. The interviews were designed to capture insights from key stakeholders and experts in the fields of ageing and digital technology. The interviews focused on the following key questions:

1. How might greater reliance on digital technology negatively affect social and economic participation in later life?

2. What are the key opportunities that digital technology might create when it comes to supporting social and economic participation in later life?

3. What actions and/or resources are needed to ensure that the risks are minimised and the opportunities can be realised?

The interviews, which were conducted by the first two authors, were kept open and flexible in order to allow participants to introduce new topics, follow interesting trains of thought and discuss subjects as they considered them. Interviewees were encouraged to discuss positives and negatives of both technology and ageing (and how they intersect), and they were assured their responses would be confidential and de-identified where necessary. Thus, social desirability should not have influenced the data and in any case we were aiming to capture (and thus interrogate) what was considered socially desirable ways of talking and thinking about technology, ageing and participation.

Participants. The participants were identified and selected for their perspectives on a thought-leadership report on digital technology, age and participation (Mason et al., 2017). The interviews provided an opportunity for a discourse analysis of the views of influential leaders with decision making power across multiple industry sectors (health, financial services, aged care, education, government, community services, facilities management, recreational services, technology providers and research) and interest groups (e.g., seniors, regional communities, digital inclusion and human rights).

Analysis. Interviews were recorded, professionally transcribed and then imported into NVIVO 10 (QSR International, 2011) qualitative analysis software. The data had already been coded for the purpose of generating themes for the report using grounded theory (Glaser and Strauss, 1967; Charmaz, 2006). The discourse analysis went back over the data to pay particular attention to key concepts, language terms, values and assumptions and to regroup the data into categories and themes around key language and value groups (Fleming and Vanclay, 2009). The coding hierarchy produced from the discourse analysis is provided in Appendix 1 (Supplementary Information).

\section{Results}

The discourses of age-technology-participation that we found encompassed issues of equity, ability, purpose, design and enjoyment. In line with the framing of the interviews (in the context of both social and economic participation), they discussed the range of ways in which older people might actively participate in society. Paid employment was included but given less focus 
than other ways of participating (presumably because of the focus on the older demographic). In contrast with previous research focusing on discourses of ageing, these interviews revealed quite a high level of positivity about ageing. Participants acknowledged that 'older people' is a broad and diverse group, with similarly broad needs, wants and ways of participating. Therefore, a contextualised view of technology is important (e.g., technology in the home, technology and work, technology in volunteering). This positive view of ageing suggests that in the context of ageing, technology and participation, the 'techtopian' myth of technology may be strong enough to subvert discourses of ageing as a negative, limiting and isolating force. At the intersection of ageing, technology and participation, two overarching discourses could be discerned, in both of which the effect of technology appeared to predominate over the effect of age. These two discourses were 1 -that technology will lead human progress and consequently we cannot predict how the future will be, instead we just need to wait and see what innovation brings; and 2-that we need to drive the development of technology to bring about the future of our own choice. These are discussed below, highlighting the nexus of technology-age-participation as appropriate.

Technology will lead human progress. The first dominant discourse-'technology will lead human progress'-focuses on technology as an agent driving changes in human society. It is based on assumptions that digital technology has come to be a social participant in its own right, exerting considerable influence over humans and driving change. There is an implicit expectation that most problems will eventually be solved by technology as it continually 'improves'. In this discourse, humans 'respond' to changes in technology; they react and change around new technology. Innovation occurs with new technology and then diffuses to human society. For example, in the first quote below, a respondent describes the relationship between digital technology and government as one in which the technology 'impacts' government. Here, the digital technology is presented linguistically as being the initiator of influence, while the government is given a more passive role, as something profoundly changed and altered by the power of the technology. In the second and third quotes we further see how human responses to technology are reactive and are rarely critically assessed, until they have already been normalised and become habit, by which time the behaviour might be difficult to change.

we do see that digital technology will impact across government, whether it's in health, in transport, in delivery of government services, the way government does its own internal business; these-the technology will profoundly impact those areas of government (Interview 5)

So people will modify their consumer behaviours around the technology (Interview 28)

So I think the iphone was a cultural revelation-for better or for worse it is my iphone, and I touch this more than I touch my children. That's not good probably, but I do, and that's changed how we communicate in a profound way (Interview 27)

Humans drive technology development. The second discourse we identified highlighted the salience and agency of humans in the human-digital technology relationship. This discourse was evident in patterns of language that, conversely to the discourse described above, bestowed the active role to humans, particularly in the development and application of technology. In this discourse, technology is a tool for people to use to achieve goals, such as reducing isolation (a particular issue for older people), reducing inequalities or improving quality of life. Harnessing and applying technology was within the power of the human, rendering it a useful mechanism for engaging people and creating new forms of participation. Controlling technology was described in terms of being an ethical obligation, as interview participants emphasized the importance of controlling potential negative aspects of technology (e.g., cyber-crime) and recognising and prioritising its benefits to social issues such as participation, connection and ensuring everyone has the opportunity to be included in meaningful and productive activities. Examples of this discourse include:

Whatever we do and how we do it, it has to be meaningful. I see a lot of very sexy technology out there which is superb, I'm just stunned at the brainiacs who built it. The problem is, is it meaningful? It might be sexy and cutting edge but actually does it have an application that means it's going to survive the process, the reality? So some of that as well needs to be considered as we move forward (Interview 35)

And they basically draw together a bunch of their IT nerds in a room with some of the people that are running these community services organisations just to have a bit of a brainstorm. What can we do? How can we help you? Is there stuff that we can bring to your things? That's delightful, you know, because it's completely random. But with both sides that are willing to give it a go; you can come up with some quite interesting solutions.... It's not enough just to bang it up on a website and expect it all to permeate through; things never work like that, and I think this is the same. (Interview 26)

Technology can also enable us to go back to those more bespoke styles of life if you like....We've used technology to disconnect ourselves from each other, but, I think, equally we can use technology to connect ourselves with each other and the environment within which we live (Interview 12)

Whatever you want to do, technology is one of the frames, and probably the most significant frame by which people are looking for solution. It becomes an important driver of not only communication but innovation, productivity, job security and to a degree food security (Interview 32)

Within these two overarching discourses, we could discern a range of other ways of describing and/or thinking about digital technology in the context of these interviews about ageing, technology and participation (see Fig. 1).

In Fig. 1, the top left hand box identifies discourses in which humans drive technology and technology is seen as positive, but age related discourses still persist, so inequities between old and young in relation to technology, remain. The top right hand box shows technology overriding age discourses (technology creates the inequity, not age).

The bottom left hand box shows how technology drives humans and older people are excluded (traditional discourses of ageing prevail). The bottom right hand box shows discourses in which technology drives humans but technology discourses surpass age related concerns so everyone is effected (in this case, disrupted).

Exploring the discourses and their implications. In this next section, we examine the individual discourses that emerged, illustrating the range of ways in which the relationship between 


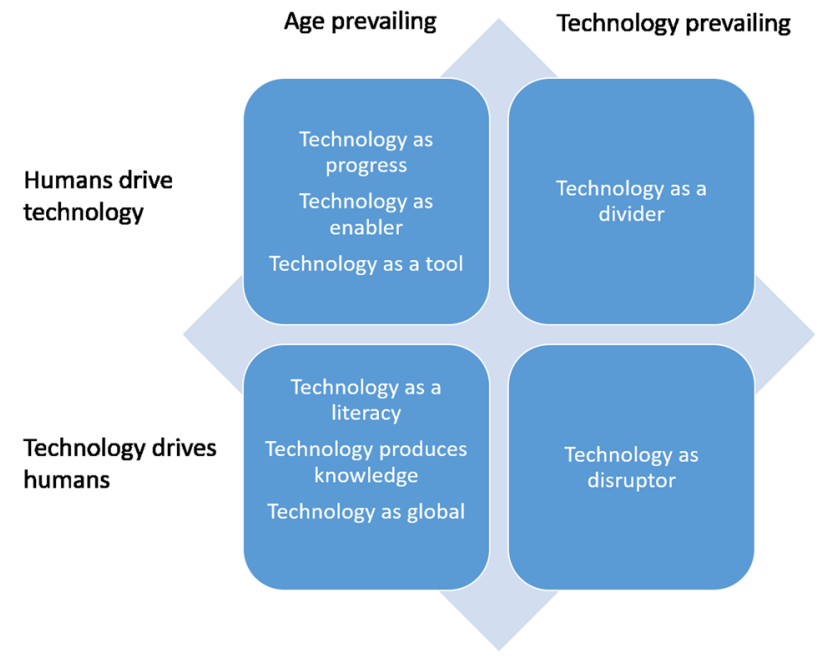

Fig. 1 The 'themes' found in the interviews organised under an overarching split of 'Humans drive technology' or 'Technology drives humans'

age and technology is framed and drawing out some of their implications.

Discourses within the 'humans drive technology' theme. Within the 'Humans drive technology' theme, technology is often described in positive terms as a tool and/or a means to support inclusive participation. For example, in the interviews participants stated:

we're already seeing it, citizens are using these tools to selforganise and solve problems in their community (Int 8)

Books, internet, these are all just tools, they're all just tools for exchange of information (Int 24)

A limitation of this discourse is that tools are regarded as objective and the ideologies around how and why tools are used are rarely examined. If technology is only a conduit to something else, it is not expected to have any positive or negative effects of its own. Yet some older Australians, who are less educated and live remotely without access to high speed broadband have less capacity to use the tools and are thus less able to achieve their ends in a society that tends to assume that these tools are available to all.

Taking the concept of digital technology as a tool a step further, another way of perceiving technology in this discourse is as part of human progress, an inevitable progression.

But the tools themselves aren't the solution, it's the relationship between what the tools are and a deep understanding of how to actually provide the social good (Int 27)

...it's going to take, I think, a generation to actually change. My generation, who's used to using digital technology, it won't be an issue as we age. But it's-until really, the sort of 60 s, 70 s and 80 year olds move on, it's not going to have the absorption, in my view, that is optimal for reliance as the only tool in what you use (Int 6)

This means technology is seen to be unavoidable, inevitable and essentially good, following the 'techtopian' myth of technology. Technology is linked to development and advancement (and the young) and it is more likely to be uncritically adopted. The current generation of the elderly are depicted as inevitably left out, as they were not able to develop the skills while growing up to keep pace with technology. There is a danger in not recognising that progress can come at significant cost. Furthermore, progress is often implicitly linked with the younger generations to bring about change.

Also within the first theme of 'humans drive technology' is a discourse about humans using technology to create opportunities to participate in new ways. For example,

the way I view digital technology is to increase or make life easier, to be honest. I don't see it as a threat. I see it as something which is an enabler of helping me go about doing whatever it is that I need to get done more efficiently (Int 15)

It's an enabling. So rather than being seen as a negative, I think used the right the way, it's an enabling technology and I think we really aren't harnessing it to the way or to the benefit that we could be (Int 10)

...often we have a bit of a deficit model when it comes to seniors...we're quite happy to say to older people, 'You know you can connect better with friends and family if you're online,'...the key thing for me is helping people understand how the Internet can help really open the opportunities for them in terms of building on their interests and connecting them with like-minded people and allowing them to participate in our democracy and participating in having a say on issues no matter what's happening in the world that they're passionate about and contributing, I guess, as opposed to just having technology as something done to them. (Int 9)

Technology as an enabler allows people to do things that they would not otherwise be able to do, either through process or outcome. It tends to be viewed positively, with less commentary about the way in which technology also enables people to do things that society might not like-breaches of privacy, online pornography etc. There is also a tendency for these discourses to focus on older people as being 'enabled by' technology, thus recipients of, rather than actors with technology. In the final quote, older people are framed as needing 'help' to understand how the Internet can 'really open the opportunities for them' rather than being actors who wield the technology in a selfdetermining manner. In this respect, prevailing discourses of age clearly moderate the extent to which older people are seen to be capable of driving technology.

Thus, while overall, 'humans drive technology' is full of positive narratives about technology, in the context of older people who may be excluded from this ability to drive technology, technology is a divider: worsening differences in wealth, skills, access and equity:

it opens the door to staying engaged longer in various activities in our life course but not for everybody, right? So there's this gap in who has access to the ability to utilise technology to enhance our lives and there's this other gap in groups that can't and don't and may never be able to in the same way (Int 27)

However, I think there is a great risk in the broad sweep of history, that these sorts of changes can have adverse consequences for particular groups of workers (Int 36)

The last discourse in this theme, 'technology as a divider' is about how people who already have access to money, resources, education, information etc. are likely to do well with technology and people who do not (perhaps especially older people) are more likely to miss out and fall further behind. This discourse 
underplays the potential for new technology to become more accessible due to falling costs of production and improved accessibility (e.g., with co-design) and reveals that only some humans have the ability to drive technology, older people being amongst those who do not.

Discourses within the 'technology drives humans' theme. In the second over-arching discourse-'Technology drives humans'several discourses can again be discerned, differing in the extent to which the effect of technology is seen to prevail, affecting all age-groups in the same way, versus affecting older people in a unique way compared to younger people.

In the discourse of technology as knowledge, technology is described positively as a way of producing 'perfect' objective knowledge. As interviewees described:

with the advent of big data you can just crunch huge amounts of quantitative data and increasingly qualitative data and trends. So you can-on a very simple search function you can say in the past 50 years what impact has the weather had on agricultural production and in an instant you can get the answer (Int 15)

the thing that changes is how much better we're getting at collecting complex data. So we're collecting more complex data and larger amounts of it. ... I can't rule out, as a scientist, there's no way I can rule out the possibility that pattern recognition wise, like what is really big in designs, may be covered by computer vision in the next 50, 100 years (Int 17)

In this way of viewing technology, machine produced data is implicitly prioritised over that produced by humans because it is seen to be more accurate and objective as opposed to subjective and unreliable. In some domains, decisions based on data delivered by technology will completely change the way work is conducted. However, there is also a loss of knowledge since most of us are not equipped to evaluate the basis upon which the algorithms reach their decisions or make a recommendation. For older people, there is also a change in the way their knowledge is valued-personal or process knowledge loses value as information searches and decision-making are increasingly automated.

Another way technology is described in this theme is as a 'literacy', a range of interlinked essential skills for participation. In this discourse, too, discourses of ageing are still evident since older people are generally assumed to lack the all-important digital literacy.

I think we definitely are going to have to have higher computer literacy skills and digital skills, and that will rise naturally, as people respond to the need to exist and pay their bills (Int 34)

...if people aren't digitally literate to start off with, how can they access that increased learning and those international communities? (Int 8)

anybody over 45 needs to be digitally aware because that's what we need as a skillset for employment... (Int 4)

....They often have many more functions than the user wants or needs, but they're there on the product and they could become a source of confusion, they can become a source of malfunction, and in my view, that's because the design did not take into account the needs of different cohorts of users (Int 37)
If technology is a literacy it is something that everyone is expected to learn and keep up with. Furthermore, by framing technology as a literacy it is linked to inherent preconceptions about individual ability (such as intelligence) rather than access to resources. Many other skills and opportunities rely on mastery of this literacy, and so it can create greater divides between those that can and those that cannot. Cost and equity are issues in developing literacies-time to learn and practice, access to teachers, resources etc. Older people are understood to be less digitally literate and therefore there is a tendency to view them as passive rather than active users of technology.

The third discourse in which 'technology drives humans' but old age continues to be a differentiator of impacts is the discourse of technology as global. Participants explain:

I worked on a project in New Zealand and a project in Victoria but I was based in the Blue Mountains. If you can deliver your services in a digital way, you'll also be able to continue working wherever you're based, even if you have to go and live in a retirement village (Int 8)

my son is working for an American firm doing work in China from Melbourne (Int 28)

In the discourse of technology as global, geography is no longer an issue and individuals can work and live anywhere, accessing support, goods and services from around the world. With the ability to overcome geography, technology sometimes also surpasses age-related barriers. For example, technology allows older people living in remote areas to access specialist medical practitioners, use robots to perform aged care work or share their knowledge and effort towards a globally important cause. Thus, mobility constraints associated with old age are circumvented by the technology.

The only discourse in the 'technology drive humans' theme in which older people are not differentiated from younger people is the one in which technology is viewed as a disruptive force. If technology is a disruptor, all, or at least many groups in society are relatively passive or disempowered in the face of its impact. In this context, age becomes less relevant and technology might actually make traditional notions of retirement and old age redundant.

Speaking to the aged care providers I have, particularly the smaller ones, they are I think, totally unprepared. They do not have the skills-they don't the understanding of the issues, and they don't have the skills and competences, or the resources, I think, to respond to them properly (Int 36)

...as we increasingly put all of our personal financial information online we're at risk of cybersecurity issues from a variety of levels, either information being stolen or misused or cyberterrorism or even cyberbullying. There's a lot of these risks of ultimately your information being taken by people that you wouldn't want to have that information (Int 15)

There's a certain Darwinism in there. So those who don't cope terribly well and don't evolve terribly well and it's not just about technology, it's about other societal changes and it's about changing income models as well; they will no longer be there and others that are good and can cope will be created and they will survive (Int 19)

This view of technology focuses more on the fallout from the major changes technology can bring to society. It accepts that 
change is inevitable, that change might also be positive, but in the process there will definitely be losses (likely to have disproportionately greater impact on already marginalised groups). It is important to acknowledge that technology will bring costs as well as benefits but there is something catastrophic in the way in which this view is expressed which ignores the potential capacity of humans to respond and adapt.

Final thoughts. This study examines the intersection of discourses relating to age, technology and participation as propounded by thought leaders and decision makers from across industry and society. Existing discourses of ageing were evident in the assumptions and preconceptions about the way in which older people will relate to technology and the ways of participating that will be most relevant to them. However, hegemonic views of technology as 'universal' and 'progressive' and relating to the ability for technology to solve all ills appeared to dominate over more age specific discourse.

Adoption of a particular discourse or related set of discourses has the potential to constrain our behaviour and decisions. For this reason, it is critical to raise awareness of discourses, especially for people with key decision making roles. Previously identified discourses of ageing (e.g., Taylor and Earl, 2015; Vines et al., 2015) demonstrate the constraints that normalised views of ageing as a limitation and a problem place on active participation in society and therefore happy, productive lives of older people. On the surface, developments in digital technology make it more feasible for older Australians to remain economically active by taking over the repetitive and physically demanding aspects of work and by facilitating new work arrangements (e.g., remote work, independent work). In so doing, technology reduces some of the barriers to economic participation (e.g., mobility constraints, competing life goals) that are traditionally associated with age. Yet technology also brings with it implicit values and assumptions that constrain its potential, such as around issues of access, universality and normalised pace of change. These disproportionately limit older people and therefore the agetechnology-participation suite of discourses is especially important to critically examine. In our analysis (specifically, in the discourse of technology as an enabler) we identified participants describing technology as surmounting the effect of age, by creating opportunities to participate in new ways. However, in some of the discourses, although digital technology could circumvent barriers associated with ageing, older people were still assumed to have a different (more passive, subordinate and disempowered) relationship with technology (and consequently, in our society). In these discourses, discourses of ageing mediated the outcomes derived from technology. While in some discourses humans could drive technology, generally older people were not the drivers. And when technology was seen to drive human progress, older people were more likely to flounder than to prosper in its wake, since they lacked the 'literacy' and required forms of knowledge to prosper. Thus, even when technology is framed as an enabler, age still creates subtle constraints. Furthermore, when we describe technology as an enabler, we risk failing to notice and consider who or what is not being enabled-especially when technology is developed and designed by a homogeneous group that is not representative of the end users.

Variability in the discourses reflects the variability in social constructions of ageing and technology and participation-none is right or wrong. However, discourses can constrain our thinking and behaviour and this study revealed some limiting assumptions about the way in which older people might engage with technology. For example, in 'technology as an enabler' older
Australians were described as using home monitoring technology to stay in their own homes for longer, using online services to do their shopping and transactions with government and using videoconferencing and social media platforms to remain connected with family and friends. Less was said about older people being enabled by technology to innovate or be more productive in the workplace. More explicitly, in 'technology as a divider' older people were seen to be at risk of being "left behind" due to their lower level of engagement and comfort with digital technology. Some participants even suggested that the problem of digital divide would disappear due to attrition or 'Darwinism'-as less digitally literate generations are replaced by the next generation of older people, who are more comfortable using technology. In 'technology as literacy', older people were described as being relatively low in digital literacy and consequently, less able to participate in a more digital society and economy. Importantly, these discourses emerged in the context of a study that specifically sought to explore the benefits as well as the risks of digital technology in the context of lifelong participation and furthermore captured the discourses of those with high levels of power over sectors that were particularly important for those later in life.

Unless challenged, these discourses framing older people as passive consumers of digital technology, may result in older people becoming further constrained in the way in which they participate in the future. For individuals and society in general, there is a substantial cost associated with older people retiring from work and other forms of participation. For example, in Australia, a recent report estimated the value of older Australians' potential contribution to the economy at around $\$ 69$ billion (PricewaterhouseCoopers, 2016). Also, perhaps because the baby boomer generation is often described as one of the wealthiest generations in history, their behaviour as consumers (as well as workers) is gradually being recognised as having important implications for the economy (Dann, 2007). Yet, until recently, there has been little priority given to developing technology which addresses the unique barriers experienced by older people in maintaining active and empowered roles. For example, remote working technology could be developed to support older workers with limited mobility, yet currently it is mainly deployed as a means of reducing human workers' exposure to hazardous work environments. Co-design initiatives, which are designed to connect technology developers with older users of the technology so as to ensure that their needs and wants are represented in the design process are meant to address this gap but decisions about when to involve older people in the co-design process may themselves reflect unconscious assumptions about when and how older people are likely to engage with technology.

Our research also revealed alternative challenging discourses, linking older people, technology and active forms of participation. However, they were outweighed by discourses focusing on more passive forms of participation. In the discourses we found relating to 'technology as an enabler' and 'technology as literacy', participants discussed digital technology as something which you can choose to engage with and choose to equip yourself with the skills for. But, concurrently, some participants realised it was increasingly not a real choice, because of the severe limitations of not engaging with technology. Given the ubiquity of technology in modern life, we believe it is necessary to raise awareness of, and challenge, limiting discourses, so as to ensure that we maximise our human potential across the whole lifespan.

\section{Conclusion}

Our work identified two overarching discourses relating to digital technology, older people and participation amongst the 
stakeholders we interviewed. In the discourse of technology as a driver of human progress, there was an assumption that technology would provide a 'fix' to the social and economic challenges that face us now and into the future, and in so doing, circumvent some (but not all) of the limitations traditionally associated with ageing. However, there was also an implied acceptance of unavoidable disruption and unintended negative consequences associated with important technological developments which were not limited to the elderly. In contrast, those who viewed technology as a tool, wielded by humans to solve challenges and problems, saw greater potential for positive changes. Although the latter discourse has its limitations, it would seem to offer a more empowered and considered stance from which to tackle future challenges (of which our ageing population is but one). If we choose to promote the latter discourse, we will need both social and political decision making processes and community feedback through which we can ensure that technology development (and the products and services that it enables) are directed towards supporting the type of future work and lifestyles that we can all aspire to enjoy in later life. Importantly, we need to be vigilant to the effect of prevailing assumptions, still reflected in discourses which depict older people choosing to participate in a more restricted, passive or subordinate way.

Received: 28 September 2017 Accepted: 9 April 2018

Published online: 08 May 2018

\section{References}

Abbey R, Hyde S (2009) No country for older people? Age and the digital divide. J Inf Commun Ethics Soc 7(4):225-242

Ahituv A, Zeira J (2011) Technical progress and early retirement. Econ J 121 (551):171-193

Angermuller J (2015) Discourse studies. In: Wright JD (ed) International encyclopedia of the social \& behavioral sciences, 2nd edn. Elsevier, Amsterdam, p $510-515$

Angermuller J, Maingueneau D, Wodak R (2014) The discourse studies reader. an introduction. In: Angermuller J, Maingueneau D, Wodak R (eds) The discourse studies reader. Main currents in theory and analysis. John Benjamins, Amsterdam, Philadelphia, p 16-36

Badham RJ (2008) Technology and public choice: strategies for technological control and the selection of technologies Prometheus 4:288-305

Bennett S, Maton K, Kervin L (2008) The 'digital natives' debate: a critical review of the evidence. Br J Educ Technol 39(5):775-786

Boulton-Lewis GM, Buys L, Lovie-Kitchin J, Barnett K, David LN (2007) Ageing, learning, and computer technology in Australia. Educ Gerontol 33 (3):253-270. https://doi.org/10.1080/03601270601161249

Brynjolfsson E, McAfee A (2014) The second machine age: work, progress and prosperity in a time of brilliant technologies. W.W. Norton \& Company, New York City

Buchanan-Oliver M, Cruz A (2011) Discourses of technology consumption: ambivalence, fear and liminality. Adv Consum Res 39:287-291

Castells M (1998) End of Millennium. Blackwell, Malden, MA

Charmaz K (2006) Constructing grounded theory: a practical guide through qualitative analysis. Sage, London

Comunello F, Fernández-Ardévol M, Mulargia S \& Belotti F (2016) Women, youth and everything else: age-based and gendered stereotypes in relation to digital technology among elderly Italian mobile phone users. Media Cult Soc. https://doi.org/10.1177/0163443716674363

Damant J, Knapp M (2015) What are the likely changes in society and technology which will impact upon the ability of older adults to maintain social (extrafamilial) networks of support no, in 2025 and in 2040?. Future of ageing: evidence review, UK Government Office for Science. Government Office for Science, London UK

Damodaran L, Sandhu J (2016) The role of a social context for ICT learning and support in reducing digital inequalities for older ICT users. Int J Learn Technol 11(2):156-175. https://doi.org/10.1504/IJLT.2016.077520

Dane SK, Mason C, O'Brien-McInally BA (2013) Household Internet use in Australia: a study in regional communities. CSIRO, Brisbane, Report number EP1310907
Dann S (2007) Branded generations: baby boomers moving into the seniors market. J Product Brand Manag 16(6):429-431. https://doi.org/10.1108/ 10610420710823799

Department of Economic and Social Affairs (2015) World population prospects: the 2015 revision, key findings and advance tables. United Nations, New York, Working Paper No. ESA/P/WP.241.

Dolphin T (ed) (2015) Technology, globalisation and the future of work in Europe essays on employment in a digitised economy. IPPR. http://www.ippr.org/ publications/technology-globalisation-and-the-future-of-work-in-europe

Fairclough N (1992) Discourse and social change. Polity Press, Cambridge

Fairclough N (1995) Critical discourse analysis. Longman, London

Fealy G, McNamara MA, Treacy MP, Lyons I (2012) Constructing ageing and age identities: a case study of newspaper discourses. Ageing Soc 32 (1):85-102

Fernández-Ardèvol M (2013) Deliberate missed calls: A meaningful communication practice for seniors? Mobile Media \& Communication 1(3):285-298

Fernback J (2007) Beyond the diluted community concept: a symbolic interactionist perspective on online social relations. New Media Soc 9:49. https://doi. org/10.1177/1461444807072417

Fisher E (2010) Contemporary technology discourse and the legitimation of capitalism. Eur J Social Theory 13(2):229-252

Fleming A, Vanclay F (2009) Using discourse analysis to better inform the practice of extension. Ext Farming Syst J 5(1):1-10

Fleming A, Vanclay F, Hiller C, Wilson S (2014) Challenging dominant discourses of climate change. Clim Change 127:407-418

Ford M (2015) Rise of the robots: technology and the threat of a jobless future. Basic Books, New York

Foucault M (1972) The archaeology of knowledge: and the discourse on language (trans: Smith AS). Pantheon Books, New York

Foucault M (1980) Power and knowledge. The Harvester Press, Sussex

Glaser B, Strauss A (1967) Discovery of grounded theory: strategies for qualitative research. Aldine Publishing Company, Chicago

Hajer M (1995) The politics of environmental discourse: ecological modernization and the policy process. Oxford University Press, London

Hajkowicz S, Reeson A, Rudd L, Bratanova A, Hodgers L, Mason C, Boughen N (2016) Tomorrow's digitally enabled workforce: megatrends and scenarios for jobs and employment in Australia over the coming 20 years. CSIRO, Brisbane, $\mathrm{AU}$

Helsper EJ, Eynon R (2010) Digital natives: where is the evidence?. Br Educ Res J 36(3):503-520

Hodge H, Carson D, Newman I, Garrett J (2016) Using Internet technologies in rural communities to access services: the views of older people and service providers J Rural Stud 54:1-10

Jorgensen M, Phillips L (2002) Discourse analysis as theory and method. Sage Publications, London

King J (2013) Discourses of ageing in fiction and feminism: the invisible woman. Palgrave Macmillan, New York

Kress G (1985) Linguistic processes in sociocultural practice. Deakin University, Victoria

Kozinets RV (2008) Technology/Ideology: how ideological fields influence consumers' technology narratives. J Consum Res 34(6):865-881. http://www. jstor.org/stable/10.1086/523289

Kuoppamäki S-M, Wilska TA, Taipale S (2017) Ageing and consumption in Finland: the effect of age and life course stage on ecological, economical and selfindulgent consumption among late middle-agers and young adults between 1999 and 2014. International Journal of Consumer Studies. http:// onlinelibrary.wiley.com/doi/10.1111/ijcs. 12353

Laclau E, Mouffe C (1985) Hegemony and socialist strategy. Verso, London

Madden CL, Cloyes KG (2012) The discourse of ageing. Adv Nurs Sci 35:264-272

Mason C, Fleming A, Paxton G \& Singh J (2017) Lifelong participation through digital technology. CSIRO report. https://research.csiro.au/lifelong/lifelongparticipation/. Accessed 14 Feb 2017.

Murtough G \& Waite M (2000) Unemployment and re-employment of displaced workers. Productivity Commission Staff Research Paper. AusInfo: Canberra.

Mosco V (2004) The digital sublime: myth, power, and cyberspace. The MIT Press, Cambridge, MA

Nixon P, Rawal R \& Funk A (eds.) (2016) Digital media usage across the life course Taylor \& Francis: e-book, London

Prendergast D, Garattini C (eds) (2015) Ageing and the digital life course. Berghahn, New York

PricewaterhouseCoopers (2016) PwC golden age index: how well are OECD economies harnessing the power of an older workforce? Sydney, AU. http:// apo.org.au/node/65940

Qualitative Software Research International (2011) Software Developer. Melbourne, Australia

Selwyn N, Gorard S, Furlong J, Madden L (2003) Older adults' use of information and communications technology in everyday life. Ageing Soc 23(05):561-582 
Taylor P, Earl C (2015) The social construction of retirement and evolving policy discourse of working longer. J Soc Policy 45(2):251-268. https://doi.org/ 10.1017/S0047279415000665

Thomas J, Barraket J, Ewing S, MacDonald T, Mundell M, Tucker J (2016) Measuring Australia's digital divide: the Australian digital inclusion index. Swinburne University of Technology, Melbourne, Melbourne, AU

Tsai HS, Shillair R, Cotten SR, Winstead V, Yost E (2015) Getting grandma online: are tablets the answer for increasing digital inclusion for older adults in the $\mathrm{U}$. S.?. Educ Gerontol 41(10):695-709. https://doi.org/10.1080/03601277.2015. 1048165

Turner F (2006) From counterculture to cyberculture: steward brand, the whole earth network and the rise of digital utopianism. The University of Chicago Press, Chicago

van Deursen A, van Dijk J, Peter M (2015) Increasing inequalities in what we do online: a longitudinal cross sectional analysis of Internet activities among the Dutch population (2010 to 2013) over gender, age, education, and income'. Telemat Inform 32(2):259-272

van Dijk TA (2001) Multidisciplinary CDA: a plea for diversity. In: Wodak R, Meyer M (eds) Methods of critical discourse analysis. Sage, London, p 95-120

Vines J, Pritchard G, Wright PC, Olivier P, Brittain K (2015) An age-old problem: examining the discourses of ageing in $\mathrm{HCI}$ and strategies for future research. ACM Trans Comput-Human Interact 22(1):2

Weller SA (2007) The labour market prospects of older workers: What can a legal case teach us?. Work Employ Soc 21:413-437

White D \& Le Cornu A (2011) Visitors and residents: a new typology for online engagement. First Monday 16(9). https://doi.org/10.5210/fm.v16i9.3171. Accessed 3 Mar 2018.

\section{Data availability}

All data analysed or generated in this study are included in the paper.

\section{Additional information}

Supplementary information: accompanies this paper at https://doi.org/10.1057/s41599018-0107-7.

Competing interests: The authors declare no competing interests.

Reprints and permission information is available online at http://www.nature.com/ reprints

Publisher's note: Springer Nature remains neutral with regard to jurisdictional claims in published maps and institutional affiliations.

(c) (i) Open Access This article is licensed under a Creative Commons Attribution 4.0 International License, which permits use, sharing, adaptation, distribution and reproduction in any medium or format, as long as you give appropriate credit to the original author(s) and the source, provide a link to the Creative Commons license, and indicate if changes were made. The images or other third party material in this article are included in the article's Creative Commons license, unless indicated otherwise in a credit line to the material. If material is not included in the article's Creative Commons license and your intended use is not permitted by statutory regulation or exceeds the permitted use, you will need to obtain permission directly from the copyright holder. To view a copy of this license, visit http://creativecommons.org/ licenses/by/4.0/.

(C) The Author(s) 2018 